\title{
Dabie Mountain Authority: A Pathway to Achieve Sustainable Poverty Alleviation Model in China
}

\author{
Noel Zhihe Liu ${ }^{1, a}$

\begin{abstract}
Shanghai World Foreign Language Academy, Shanghai, 200033, China
\end{abstract} \\ *Corresponding author. Email: angela@cas-harbour.org
}

\begin{abstract}
This paper aims to address the issue of unsustainable and unbalanced development in Dabie Mountain region in China, by applying poverty alleviation ideas from Tennessee Valley Authority (TVA) in the United States. The issues lying under the mirage of wealth in Mt. Dabie region-the lack of a long-term plan for development and prioritization of political interest over economic interest are firstly identified. TVA's solutions to these problems include planning a well-defined poverty alleviation strategy and designing a market-based nature. Equipped with the knowledge, the author draws the blueprint of Dabie Mountain Authority, which is a nationowned enterprise incorporating market forces. The advantages of such model appear to be its efficiency (both allocative \& productive), sustainability and balanced political objectives. The disadvantages of such model emerge in the potential issue of monopoly and corruption. Further studies can be made to explore the influence of such administration in domestic market.
\end{abstract}

Keywords: Tennessee Valley Authority, Dabie Mountain, Poverty Alleviation

\section{INTRODUCTION}

Over the past decades, Chinese government has launched various lift-poverty initiatives. Most of these initiatives follow the "Big Push" model, under which the government introduces sizable financial aids to the poor regions to make "a Big Push involving increased investment, leading to a takeoff in per capita income"[1]. An exemplary case is Dabie Mountain region, which was used to be one of the country's poorest places. In 2018, the government provided CNY 12 billion fiscal funding for poverty alleviation in Anhui Province, of which CNY 9 billion were distributed to Mt. Dabie region for infrastructure, environmental issue and subsidies for local residents[2]. The numbers increased by $25 \%$ from the prior year. According to the central government, the lift-poverty initiatives in Mt. Dabie area are successful, and as a result, "the counties in Dabie region including Yuexi County are taken out of the national Poverty Region list"[3]. However, as time goes by, failures in the poverty alleviation policies start to appear-including inefficient use of funds, unorganized local development, and hence the tendency to enter poverty again. This paper seeks to replace the current poverty alleviation policies with a long-term development model. Learning from Tennessee Valley Authority, the author establishes a similar administration-a state-owned enterprise with main businesses in plantation, production and distribution of Fulin (Poria cocos)-in order to achieve an efficient, organized and sustainable regional development. Tennessee Valley Authority (TVA) was established in 1933 to promote local development. "During its 70-year operation, the region's manufacturing employment grows significantly and rapidly compares to that of other similar region in the country[4]." Though it had received government subsidies for the first few years, by 1960, it has become "a fiscally self-sustaining entity", which demonstrates the success of TVA's business model and the relevant economic policy. Thus, TVA became "a model for the United States' later to help modernize agrarian societies in the developing world"[5].

\section{METHODS AND ANALOGY}

\subsection{Issues in Poverty Alleviation Policy in Mt. Dabie}

The first problem in Mt. Dabie region is a steady and unstoppable outmigration in Dabie area. The alleviation of poverty is unable to stop the steady outmigration, a typical case of brain drains. The registered population (registered population refers to population with $\mathrm{Hu} \mathrm{Kou}$ ) in Liu An, the central city of the Mt. Dabie region, amounts to 7.17 million in 2019 , however only 5 million currently live in the city and the rest are all working outside. Fu Yang is another important city of Mt. Dabie area, and the outmigration population accounts for $33 \%$ of total, which ranks No. 2 of population outmigration in China.

The second issue is that the local households have lost their major source of income as a result of local government's prohibition against planting Fulin. Fulin, also called Poria cocos, is a fungus in the family Polyporaceae. It is a wooddecay fungus but has a subterranean growth habit. It is notable in the development of a large, long-lasting 
underground sclerotium that resembles a small coconut. This sclerotium called "(Chinese) Tuckahoe" or fu-ling(pīn yīn: fú líng), is not the same as the true tuckahoe used as Indian bread by Native Americans, which is the arrow arum. It is used extensively as a medicinal mushroom in Chinese medicine. Fulin was a major crop in Mt Dabie area but plantation of Fulin parasitizes trees and may cause permanent damage to the forest. After 2013, when President Xi's administration prioritized environmental protection, local government strictly prohibited the plantation. Farmers who breached law paid high penalties.

A steady flow of people outmigration and loss of income sources suggest that the growth of regional per capita income could be a mere illusion created by direct government subsidies. In fact, the region continues to receive government subsidies even after it has been taken out of national poverty region list.

\subsubsection{1st Root Cause: Lack of a Sustainable Economic Growth Model}

Current poverty alleviation policy in Mt. Dabie region follows the country's traditional approach, under which the government provides direct financial subsidies to those poor villages. The government subsidies are usually spent inefficiently via even allocation to various areas such as building general infrastructures and subsidizing poor families.

Under such policies, a significant improvement of factors of production does not occur in local agricultural industry, especially of heavy machinery and land scale. This is probably caused by threshold effect as the capital stock becomes useful only when it meets a minimum standard [6]. Therefore, farmers cannot enter long run development (since at least one production factor is fixed) and cannot take advantages of economies of scale.

A 70-year-old farmer in County Yuexi complained that he had planted tea trees, Mulberry trees, crops and silkworm trees simultaneously on a nearby hillside. However, he could not make profit from any of these agri-products due to their high costs. The limited scale of production and lack of technologies make it impossible for farmers in Dabie mountain to compete with other domestic producers. Lacking of business profit, the development in Dabie mountain cannot sustain. The central government is also aware of the issue and starts to allocate government fund in a more specialized area or industry.

\subsubsection{2nd Root Cause: Political Conflicts vs. Economic Conflicts}

Currently, local development goals are carried out by local government, who follows highly hierarchical relations with the central government. Lacking of economic interests and burdening huge political pressure, local administration tends to omit local economic returns and take superficial measures to meet central government's objectives.
Prohibition of Fulin plantation is a good example. When the environmental protection initiative was released, the local government responded in an inconsiderate and superficial way. It simply closed down most Fulin producers without cushioning the possible consequences such as unemployment issues and loss of income sources. It ought to be achieved in a more positive way like subsidizing technologies or employing a market-oriented policy. Therefore, the author characterizes it as a classical policy failure in central planning economy due to the bureaucratism and lack of flexibility resulting from a strictly hierarchical administration.

\subsection{TVA Model}

The original purpose of 1933 TVA-set forth in the TVA Act-was to address the Valley's most important issues in energy, environmental stewardship and economic development. The tasks of TVA initiated from water management and then further expanded to other areas covering economic development and social programs. Along with these projects, a variety of jobs were created for the unemployed people in this region. TVA was founded in May 1933 and in 1934 it employed more than 9,000 people[7].

The key factor of TVA lies under "the technique to reconcile over-all planning with the values of democracy"[8]. Lots of literatures discussed about this feature, including David E. Lilienthal's TVA: Democracy on the March, C. Herman Pritchett's The Tennessee Valley Authority: A Study in Public Administration and Herman Finer's TVA: Lessons for International Application. Others debated about centralplanning versus free market theories in TVA. However, it is undeniable that the initial government fund as well as the development strategies under the central-planning model are key successful factors for TVA in particular during the Great Depression time.

Despite its government ownership, TVA is operated on a commercial basis and achieves its goal to address local natural, economic and social issues. As Neuse pointed out, "TVA was envisioned not only as a provider, but also as a regional economic development agency that would use federal experts and rural electrification to help modernize the rural region's economy and society[9]."

The author identified some key successful factors of TVA as the following points.

\subsubsection{Efficient usage of government fund}

Under old Big Push model, the financial subsidies from the central government are usually arbitrarily distributed to many aspects in the region without much focused fields. However, TVA demonstrates that a well-defined, specialized strategy will be more beneficial.

Under the influence of the threshold effect, government subsidies would be more efficient to be used on a more selective basis-focusing on the sector that has the most 
potentiality to grow. TVA is born with a mission to manage the water resource in Tennessee Valley. Its funds are distributed to specialized fields in a well-planned manner. According to Arthur E. Morgan, the first chairman of TVA, two thirds of government budget for TVA in the first several years were exclusively spent on the construction of its hydroelectric dams[10]. Morgan and his team believed the high quality of engineering was one of key successful factors TVA's long-term operation. Later, when building local infrastructure, TVA also put majority of the funds in developing water transportation, which again turned out to be an effective strategy for boosting business in the long run. The result is fruitful-"the availability of low-cost electricity has attracted large numbers of businesses and industries to the area, and a 630-mi $(1,014-\mathrm{km})$ navigation channel extending from the mouth of the Tennessee River to Knoxville, Tenn."[11]. The rivers which used to cause flood disaster are now turned into an engine of growth.

\subsubsection{Operated on a commercial and market- driven basis}

Despite its shares being owned by the federal government, TVA operates exactly like a private corporation. TVA is governed by the company's Board, under which there are a group of professional managers led by the CEO. As the company website states, "The responsibilities of the Board include establishing company strategies, goals and objectives; setting long range plans and policies; and ensuring their implementation by the TVA staff, which is led by the Chief Executive Officer." The Board members are nominated by the President of the United States, however none of them are government officers, freeing them from political pressure. The chairman of the Board currently is Mr. James Thompson, who is a veteran of banking industry and his term expires in May 2021.

TVA's business model is commercially competitive. Under the TVA Act, the company is required to set power rates on a commercial basis and shall not rely on government subsidies to run the business. Throughout years of development, TVA has successfully achieved commercial success. It receives investment-grade ratings from international rating agencies (Moody's Aaa/S\&P AA+), which demonstrates the company's strong repayment capabilities. Also, as can be seen from the company website, "TVA receives no taxpayer funding deriving virtually all of its revenues from sales of electricity. TVA's debt securities are not the obligation of the US government and do not carry a government guarantee."

Initially fostered by government fund and sponsored by the US government, particularly by President Franklin D. Roosevelt, TVA has grown into a business that is financially independent and commercially viable.

\subsubsection{Managing political conflicts}

Consistence between regional development and macroeconomic objectives is vital for long run success of government-driven poverty alleviation. A successful development model always strikes a balance between maximizing regional interests and meeting national missions. The establishment of TVA itself is a means to meet both national and regional end.

Worth mentioning, national policies are dynamic and not always friendly to the company. However, TVA administration manages the conflicts and makes good move in business strategies. In 1980s, as the national environmental awareness increased, TVA faced huge challenges in business development. In Tennessee Valley Authority v. Hill, U. S. Supreme Court ruled in favor of protecting local species which in turn canceled the Tellico Dam Project and threatened the agency's future growth. In response, Chairman Marvin T. Runyon launched the nuclear program and instituted a rate freeze that continued for ten years[12]. Under these efforts, the company grew a more diversified portfolio of power generation including nuclear and new energy. This is vital for the company's long-term survival, given the fact that various traditional coal-fired power plants have phased out of business in recent years due to environmental problems.

\section{APPLICATION OF TVA MODEL}

The author views TVA model as one of the possible antidotes to unsustainable growth in Mt. Dabie region. The key to long-term development in Mt. Dabie is to develop a similar state-owned corporation (Dabie Mountain Authority, or DMA) which can leverage local resource to develop a sustainable economic model in Mt. Dabie. Despite state-owned nature, DMA shall be operated on commercial basis and managed by professional managers who are market-driven and capable to manage political conflicts. Such authority is expected to effectively combine market economy values and central-planning values to achieve efficient use of government funds and sustainable development.

\subsection{Operating Model of DMA}

Following the business and governance model of TVA, DMA is established by the central government as a stateowned enterprise with main businesses in plantation, production and distribution of Fulin(Poria cocos) and possibly other Chinese herbs in Mt. Dabie region. The longterm goal is to develop the region into a major manufacturer of traditional Chinese medicine and attract various medical businesses into the region. In addition to the commercial goals, DMA also has the mission to address local poverty and environmental issues, and to improve overall economic and social conditions in Mt. Dabie region. 
Board of Directors of DMA are nominated by the central government but none of them serves the government directly. A team of management led by CEO shall be hired under the Board. These people can be selected from the senior or middle-level managers in other state-owned Chinese medicine manufacturing companies who are either industry specialists or professional managers. Experienced local planters shall be also included in the management team as they are most familiar with local issues and solutions.

The initial capital of DMA is paid by the central government from Poverty Alleviation funds, used to be evenly or inefficiently allocated to villages or individuals. Like TVA or other private companies, DMA shall formulate its business strategy in production, sales, finance and business growth. In particular, the management of DMA shall form a practical and balanced strategy in addressing environmental issues arising from Fulin plantation. Instead of planting Fulin by individual family in various areas, DMA shall make a more organized and scientific way for massive plantation of Fulin. The target is to create enough jobs through Fulin businesses (including planting, marketing, administrative, etc.) while control the risks of environmental damages.

During the start-up period, DMA may suffer financial losses, which is common for companies at the initial stage. Nevertheless, after a couple of years' operation, DMA shall develop a matured business in Chinese medicine industry. A steady cash flow can be generated from the business to fund the operating cost and expenses so that a sustainable economic model shall be achieved. What is more, government subsidies should be ultimately eliminated.

\section{DISCUSSION}

\subsection{Prospective Industry: Fulin and Other Traditional Medicine}

\subsubsection{Large Potential Market}

The consumer demand on the domestic market for Fulin is large and steady. Estimated annual demand for Fulin is 10 to 20 million kilograms[13]. Current market price of Fulin (processed) is 20 to $30 \mathrm{RMB}$ per $\mathrm{kg}$, depending on the quality. Compared with other local specialties of Mt. Dabie (such as tea leaves, chestnuts and persimmons), the demand for Fulin is in relatively inelastic price, since it is popularly required in Chinese medicine prescription. This is a market with potential value of 200 million to 600 million RMB. Worth mentioning, the current market supply is largely behind the demand as currently annual Fulin output is 3 to 5 million $\mathrm{kg}$.

Mt. Dabie region has comparative advantages in producing Fulin in domestic market. Dabie Mountain was a traditional Fulin producer for years before the prohibition act, certificated by National Medical Products Administration in 1985 and 1995 respectively. Excellent geographic, climate conditions, and experienced labor ensure Mt. Dabie to be a very prospective Fulin producer.

In addition, Fulin is mainly traded domestically and is less impacted by current international trade tensions, crossborder control or other factors that are related to foreign country policies. Ensuring a large and stable demand is important during the initial development of a region as it provides a strong motive and suitable environment for DMA to grow and thrive.

\subsubsection{Environmental concerns}

Damaging environmental effects from Fulin plantation, including vast consumption of wood and soil depletion, can be overcome by organized production. Literatures suggest crop rotation and fixing amount of wood nourishment can decrease the consumption of wood per unit output and alleviate soil depletion effect[14]. The requirements can be achieved efficiently if Fulin is produced on a larger scale. Since Fulin is a common traditional medicine, it is necessary to have a high price elasticity of demand. Therefore, the current regulation on banning Fulin production will not lead to a significant decrease in its quantity demand, and may even foster black market. The more effective solution would be taxing the harmful effects on environment during the production process. It can create incentives for firms to improve (clean) technologies. Nevertheless, it allows the market to adjust supply and demand through price mechanism, avoiding the creation of black market.

\subsection{Balancing Between Local and Central Objectives}

In Section 3, it can be seen that one of the failures in current Chinese poverty alleviation policy is the inability to deal with political pressure. However, working to achieve alignment between national and local objectives is crucial for the region's long-term development. The administrative structure of DMA provides both flexibility and motivation for dealing with such conflicts.

\subsubsection{Decentralized administrative model}

"Managerial autonomy"[10], or allowing DMA to make management decisions by their own, provides the flexibility for the Board to deal with policy conflicts. It can be achieved by the separation of development agency (DMA) and the central government. Only the Board has relations with government, but they do not serve the government directly and other staff are hired by the company. Therefore, the commercial nature of the agency helps the management staff to draw a line between economic interest and political objectives-they act more independently without political restrictions.

Localization, or to maximize the engagement of local people and communities in the business, is another 
important feature of DMA which provides incentives to contribute to regional interests. This can be achieved by ascertaining a minimum ratio of staff who are inhabitants of Dabie Mountain. As a private company, DMA still takes social responsibilities (CSR) and carries a mission of poverty alleviation, so it is crucial to ensure the locals build their own wealth through the project. In addition, a major population employed by the company can also motivate the formation of local identity and the development of education system. These changes can effectively curb brain drain problem.

\subsubsection{Incorporating economic interest}

One of the ultimate goals of DMA is to become a financially independent entity. This goal provides economic incentives for DMA to deal with political pressure. Therefore, in advance, DMA and the government should designate time lines for the withdrawal of funds, which will be carried out gradually. What is more, instead of assigning pure political tasks and obligations to DMA, central government should employ more market-driven approaches to influence DMA's policy (tax/industrial policies), rendering it a more flexible and commercial driven environment.

Operating in a commercial environment, DMA can improve the status quo by providing more reasonable and sustainable income sources for local people. In short, the poverty alleviation project should act as a wealth generator rather than a funds distributor.

\section{CONCLUSION}

This paper focuses on the poverty alleviation issues in one of the most typical Chinese lift-poverty places-Dabie mountain region. By recognizing the existing problem in poverty alleviation policies and the successful factors in Tennessee Valley Authority, the author proposes a more sustainable model of development for Dabie mountain, Dabie mountain Authority.

The central idea is to reconcile market-economy values and central planning values in China's poverty alleviation initiatives. In China, one of the most important issues that prevents efficient usage of funds is an excessive central planning economy, which greatly politicizes the whole poverty alleviation project. In response to such problem, the author brings in more commercial elements to DMA, which aims to be a self-sustaining agency and pursues economic interests from its birth

The problem of DMA includes corruption and monopoly. Corruption problem is common particularly in projects related to government funds. However, a monopoly market is harmful to consumers and other domestic producers. The establishment of DMA provides a new perspective to learn from international poverty alleviation project. The idea of DMA itself is also a great example for other domestic applications. Further studies can be conducted in the efficiency problem of DMA on a national scale such as how will DMA interact with other domestic producers and consumers.

\section{ACKNOWLEDGMENT}

First and foremost, I would like to show my deepest gratitude to my teachers and professors in my university, who have provided me with valuable guidance in every stage of the writing of this thesis. Further, I would like to thank all my friends and roommates for their encouragement and support. Without all their enlightening instruction and impressive kindness, I could not have completed my thesis.

\section{REFERENCES}

[1] W. Easterly, and R. Levine. "The European origins of economic development." Journal of Economic Growth 21.3 (2016): 225-257.

[2] Anhui Province Audit Office. 2018 Anhui province financial report. Anhui: National Audit Office of the People's Republic of China, 2018. [Accessed on 1 Apr. 2020]

[3] The State Council of People's Republic of China. China Poverty Alleviation and Development Framework 20112020. Beijing: The State Council of People's Republic of China, 2011. [Accessed on 5 Apr. 2020]

[4] Kline, Patrick, and Enrico Moretti. "Place based policies with unemployment." American Economic Review 103.3 (2013): 238-43

[5] D. Ekbladh, "Mr. TVA": grass-roots development, David Lilienthal, and the rise and fall of the Tennessee Valley Authority as a symbol for US Overseas Development, 1933-1973." Diplomatic History 26.3 (2002): 335-374.

[6] Sachs, D. Jeffrey, and W. John McArthur. "The millennium project: a plan for meeting the millennium development goals." The Lancet 365.9456 (2005): 347-353.

[7] History.com Editors. (2017) TVA https://www.history.com/topics/great-depression/historyof-the-tva.

[8] P. Selznick, TVA and the Grass Roots: A Study in the Sociology of Formal Organization. University of California Press, 1949. Accessed 1 Feb. 2020.

[9] Neuse, M. Steven. "Tennessee Valley Authority (TVA)." In: Encyclopedia of the Great Depression, edited by Robert S. McElvaine, vol. 2, (Macmillan Reference USA, 2004), pp. 972-979. [Accessed on 13 March 2020] 
[10] M. Arthur Ernest. Making of the TVA. Prometheus Books, 1974.

[11] "TVA." The Columbia Encyclopedia, 6th ed., The Columbia University Press, 2018. [Accessed on 12 Feb. 2020]

[12] D. Mansfield, (July 6, 1999). "TVA SHAPED VALLEY OVER COURSE OF DECADES NEW DEAL AGENCY TAMED A RIVER, CHANGED MANY LIVES IN IMPOVERISHED RURAL AREAS". Birmingham News.

[13] F. S. Yang, and D. S. Zhao "Poria production by using pine-tree remnants." China Linfu specialties 1 (1991): 13.

[14] K. Q. Wang, et al. "Status quo and industrial policies of Hubei Poria production." Modern Chinese Traditional Medicine 14.12 (2012): 24-27. 